\title{
PSICODRAMA, BULIMIA NERVOSA NA ADOLESCÊNCIA E AFETIVIDADE
}

\author{
Juliana Soares Guimaraes ${ }^{1, *}$ (D) Maria da Penha Nery ${ }^{1}$ (D)
}

\section{RESUMO}

A adolescência é um período marcado por diversas mudanças biopsicossociais, como, por exemplo, a corporal. Quando essa mudança não corresponde ao padrão de beleza estabelecido socialmente, o adolescente precisa lidar com frustrações e preconceitos, o que pode levá-lo ao adoecimento. A presente pesquisa é um estudo de caso de uma adolescente que sofria de Bulimia Nervosa. Neste artigo apresentaremos os resultados da psicoterapia psicodramática, principalmente do trabalho terapêutico da criança interna ferida e de lógicas afetivas de conduta que favoreceram a melhoria de seu transtorno alimentar. Também analisaremos como o corpo carrega as cenas socioculturais, na busca de afetos nas relações. Ao reviver essas cenas, na realidade suplementar, a paciente pode ressignificar experiências de sofrimentos que liberaram a espontaneidade-criatividade e desenvolveram modalidades vinculares menos sofridas.

PALAVRAS-CHAVE: Bulimia Nervosa; Adolescência; Psicodrama; Afetividade; Transtornos alimentares.

\section{PSYCHODRAMA, BULIMIA NERVOSA IN ADOLESCENCE AND AFFECTIVITY}

\begin{abstract}
Adolescence is a period marked by several biopsychosocial changes, such as the body. When this change does not correspond to the socially established standard of beauty, adolescents need to deal with frustrations and prejudices, which can lead them to become ill. This research is a case study of an adolescent who suffered from Bulimia Nervosa. In this article we will present the results of psychodramatic psychotherapy, especially the therapeutic work of the wounded inner child and the affective logic of conduct that favored the improvement of her eating disorder. We will also analyze how the body carries the socio-cultural scenes, in the search for affections in relationships. By reliving these scenes, in surplus reality, the patient can re-signify experiences of suffering that have released spontaneity-creativity and develop less suffered vincular modalities.
\end{abstract}

KEYWORDS: Bulimia Nervosa; Adolescence; Psychodrama; Affectivity; Eating disorders.

\section{PSICODRAMA, BULIMIA NERVIOSA EN LA ADOLESCENCIA Y AFECTIVIDAD}

\section{RESUMEN}

La adolescencia es un periodo marcado por numerosos cambios bio-psicosociales, como, por ejemplo, el corporal. Cuando este cambio no corresponde al canon de belleza establecido socialmente, el adolescente debe enfrentarse a las frustraciones y prejuicios, que pueden llevarlo a enfermarse. Esta investigación es un estudio de caso de una adolescente que sufría de Bulimia Nerviosa. En el

1.Associação Brasiliense de Psicodrama, Brasília (DF), Brasil.

*Autora correspondente: jusoaresg@hotmail.com

Editor de Seção: Rosalba Filipini

Recebido: Out. 29, 2020 | Aceito: Jan. 21, 2021 
presente artículo se presentarán los resultados de la psicoterapia psicodramática, principalmente del trabajo terapéutico de la herida infantil y de la lógica afectiva de conducta que han favorecido la mejoría de su trastorno alimentario. También se analizará cómo un cuerpo carga con las escenas socioculturales, en la búsqueda de afecto en las relaciones. Al revivir esas escenas en la realidad suplementaria, la paciente logró resignificar experiencias de sufrimiento que liberaron tanto la espontaneidad como la creatividad y desarrollaron modalidades vinculares menos dolorosas.

PALABRAS CLAVE: Bulimia Nerviosa; Adolescencia; Psicodrama; Afectividad; Trastornos alimentarios.

\section{INTRODUÇÃO}

Nossa pesquisa é fruto do trabalho com adolescentes em uma clínica multidisciplinar de Brasília. Trabalhar em clínica multidisciplinar nos enriquece profissionalmente de diversas formas. As trocas de conhecimentos, supervisões e estudos de casos nos ajudam na criação adequada do vínculo terapêutico e na busca de aperfeiçoamento das pesquisas de nossas práticas.

A adolescência nos fascina por ser um período repleto de inovações e desafios. Decidimos por atender essa clientela na clínica e, ao longo da experiência profissional, chegamos aos objetivos e perguntas deste estudo.

Este artigo tem por objetivo geral descrever os resultados alcançados, por meio da psicoterapia psicodramática, em um estudo de caso de uma adolescente que sofria de Bulimia Nervosa. Também analisaremos a pergunta de como a Bulimia Nervosa nos apresenta o corpo que carrega as cenas socioculturais, na busca de afetos nas relações. O corpo se expressa e nos expressa. O Psicodrama dá visibilidade a essa expressão, por meio de cenas. As cenas revelam o campo sociométrico da paciente e seus aprendizados emocionais relacionados às lógicas afetivas de conduta e à criança interna ferida.

Um objetivo específico é apresentar como o trabalho terapêutico da criança interna ferida e das lógicas afetivas de conduta adotadas pela paciente favoreceu a desconstrução de seu transtorno alimentar.

Ao atender adolescentes, identificamos que a maior parte delas apresentava demandas envolvendo imagem corporal, e levantamos várias questões sobre esse fato, dentre elas: a) a Bulimia Nervosa apresenta o corpo que carrega as cenas socioculturais na busca dos afetos nas relações?; b) a matriz de identidade dinâmica e do momento da paciente, com suas questões socioculturais, reforçaria a criança interna ferida, ao atuar negativamente na imagem corporal e na autoestima?; c) haveria lógicas afetivas de conduta relacionadas à imagem corporal que promoveriam modalidades vinculares em sofrimento?; d) o enfoque do trabalho terapêutico sobre a criança interna ferida e lógicas afetivas de conduta poderia contribuir para a melhora do quadro clínico de Bulimia Nervosa?

A paciente escolhida para o presente estudo se trata do caso mais extremo que atendemos, motivo pelo qual optamos por realizar este estudo de caso, como forma de contribuir para quem trabalha com adolescentes e transtornos alimentares.

Bulimia Nervosa consiste em episódios recorrentes de compulsão alimentar seguidos de práticas compensatórias para evitar o ganho de peso, como: exercícios físicos em excesso, vômitos e uso de medicações. Ocorrem no mínimo uma vez por semana durante três meses (APA, 2014).

Nesta pesquisa realizamos, portanto, um estudo qualitativo de um caso, com uso de métodos terapêuticos de ação, dentre eles, Psicodrama e jogos dramáticos, e fizemos os processamentos teóricos de quatro sessões. Descrevemos as sessões e análise documental do prontuário da participante, atendida em uma clínica multidisciplinar.

A adolescência é um período de diversas mudanças biopsicossociais, na qual o sujeito se encontra na saída da fase infantil rumo à fase adulta. Nessa transição, o adolescente tenta conciliar a busca de reconhecimento do "eu" frente a tantas mudanças internas e externas — que lhe exigem maior autonomia a respeito de seus responsáveis -, ao mesmo tempo em que busca formas de inserção social, que nesse período adquire um maior peso em suas vidas.

Vivemos em uma sociedade capitalista, em que o consumo, a individualização, as lutas entre grupos sociais e classes vigoram, trazendo ideologias para o exercício social de poder (Foucault, 1979/2014; Guimarães, 2002).Vivemos na sociedade do espetáculo, em que o indivíduo vira mercadoria, e a todo momento muitos são expostos para a visibilidade dos padrões 
sociais, que em sua maioria excluem pessoas e grupos (Debord, 2007). Em nossa sociedade, portanto, os adolescentes são submetidos a determinados padrões de beleza corporal.

Com isso, muitos adolescentes se sentem frustrados e vivem preconceitos quando suas alterações físicas não caminham em direção à imagem corporal idealizada por diversos tipos de mídias e grupos. Muitos relatam experiências de discriminações relativas ao corpo desde a infância. Em casos de sobrepeso, isso é mais frequente. Alguns adolescentes, diante da frustração vivenciada - em busca de reconhecimento e pertencimento —, acabam por desenvolver quadros de ansiedade, depressão e/ou transtornos alimentares.

No caso da busca de reconhecimento e pertencimento através da imagem corporal, muitos adolescentes começam a praticar exercícios físicos de maneira exacerbada, alguns apresentam compulsões alimentares seguidas de vômitos, outros realizam jejuns, dentre outras práticas. O que nos mostra que até um processo natural de saciação de uma necessidade básica - no caso do alimentar-se - pode estar carregado de um processo de culpa, sofrendo transformações insalubres, que podem se estruturar em um transtorno alimentar.

Segundo Moreno (2014, p. 114), a "matriz de identidade é a placenta social da criança". Nesse sentido, a família e demais meios sociais têm grande influência e responsabilidade no desenvolvimento biopsicossocial do sujeito. A família e os meios sociais podem contribuir tanto para a promoção de saúde quanto para o adoecimento, quando está muito suscetível às conservas culturais ${ }^{1}$ que causam o bloqueio da espontaneidade ${ }^{2}$-criatividade e, consequentemente, sofrimento.

Avançamos na leitura da matriz de identidade como dinâmica e atuante no aqui e agora em nossas vidas (Nery, 2014). Não restringiremos nossos casos clínicos aos problemas familiares e a fases estanques de desenvolvimento, mas também trazemos as questões socioculturais e econômicas constituintes das relações e da subjetividade dos pacientes.

No processo de adoecimento, alguns conceitos nos ajudam a compreender esse entrelaçamento indivíduo/família/ sociedade. $\mathrm{O}$ conceito de criança interna ferida nos fala do registro emocional e comportamental da pessoa que não encontrou, em várias situações (familiares e sociais) de sua infância, o suficiente alimento psíquico - cargas afetivas para suas necessidades de dependência (Cukier, 2017).

Nery (2014) complementa os estudos sobre a aprendizagem emocional afirmando que, ao longo da vida, a pessoa desenvolve as lógicas afetivas de conduta, ou seja, crenças de comportamentos que podem trazer algum alimento psíquico do seu meio social, ou manifestar a frustração em relação a sua falta. As lógicas afetivas de conduta fornecem os direcionamentos das ações no campo sociométrico (ou seja, nos pertencimentos grupais, nas escolhas, identificações, atrações e rejeições entre as pessoas). Elas trazem as resoluções afetivas para algum equilíbrio psíquico, resoluções essas que podem ser criativas ou conservadas.

Dentro das teorias contemporâneas do Psicodrama, para o entendimento do caso, também consideramos fundamental o conceito de "papel complementar interno patológico", de Bustos (2005). Papel complementar interno patológico se refere à internalização de conflitos que se dão entre seu próprio papel com o papel complementar e trazem sofrimento incapacitante.

Focamos esses conceitos, pois eles ajudam no raciocínio psicodramático clínico, na compreensão dos sintomas, sofrimentos e conservas de conduta da paciente e auxiliam operacionalmente no manejo psicoterápico, seja na estratégia de horizontalização, de cenas do aqui e agora, ou da verticalização, com a presentificação de cenas do passado.

Apresentaremos como o enfoque do trabalho terapêutico da criança interna ferida e das lógicas afetivas de conduta adotadas pela paciente favoreceu a desconstrução de seu transtorno alimentar, para o desbloqueio da espontaneidadecriatividade e para modalidades vinculares menos sofridas.

\section{MÉTODO}

O presente estudo se trata de uma pesquisa qualitativa, na qual foi realizado um estudo de caso através da metodologia psicodramática, como estratégia de compreensão e intervenção. Segundo Minayo (2012, p. 623), “o verbo principal da análise qualitativa é compreender”, entendendo-se por compreender a capacidade de colocar-se no lugar do outro, considerando a singularidade desse indivíduo.

1.Quando "uma ideia criadora é guardada para sua preservação e repetição" (Moreno, 2014, p. 175).

2.Responder adequadamente a uma nova situação ou de maneira criativa a uma situação antiga (Moreno, 2014). 
Na pesquisa em Psicodrama, os pesquisadores "sabem como conhecer, dominam os métodos; pesquisados conhecem o que pode ser conhecido em sua experiência; e a atuação conjunta gera um saber específico que beneficia a ambos” (Brito, 2006, p. 37), preservando a singularidade da experiência subjetiva.

Apoiado no princípio da espontaneidade-criatividade da Socionomia e nos conceitos de lógicas afetivas de conduta e criança interna ferida, este trabalho apresenta a compreensão das relações em sofrimento da adolescente em relação a si e ao mundo sociocultural que a circunda.

\section{PARTICIPANTE}

O presente estudo contou com a participação de uma paciente adolescente, atendida em uma clínica multidisciplinar. Ao buscar para iniciar um processo psicoterápico, em março de 2018, Clara (nome fictício) tinha 15 anos e estava cursando o $1^{\circ}$ ano do Ensino Médio de uma escola privada. Trata-se de uma adolescente branca, de classe média, que mora com os pais e sua irmã mais velha — três anos de diferença.

Apresentava queixa de Bulimia Nervosa, caracterizada por compulsões alimentares seguidas de compensações através de vômitos, exercícios físicos em excesso e uso de medicações para emagrecimento. Além da Bulimia Nervosa, a paciente se queixava de ansiedade generalizada, que a levava aos episódios de compulsão alimentar. Posteriormente, vivenciava um processo de culpabilização, que a levava às práticas compensatórias e desencadeava sentimento de frustração.

\section{PROCEDIMENTOS}

Foram realizadas 43 sessões de psicoterapia psicodramática bipessoal, com duração de 45 minutos cada. Dentre elas, também foram realizadas sessões de orientação aos pais, para melhoria da sua rede de apoio.

Durante as sessões, foram utilizados métodos psicodramáticos, com trabalho dos personagens e cenas da protagonista (paciente); jogos dramáticos, trabalho da protagonista por meio lúdico e teatro espontâneo, buscando a criatividade, vivencialmente, nas situações-problema. Nesses métodos usamos as etapas da sessão: aquecimento, dramatização e compartilhamento, e as técnicas de ação: solilóquios, duplos, inversões de papéis, espelhos e concretizações, contextualizadas em cenas abertas ou vivências internas.

Relataremos o caso, e selecionamos quatro sessões para ilustrar a sua análise e processamento teórico-socionômico.

\section{PROCESSAMENTO TEÓRICO DE SESSÕES}

A paciente Clara chegou até nós por meio de indicação da sua antiga terapeuta, o que facilitou a criação do vínculo terapeuta-paciente. A adolescente compareceu na primeira sessão já contando suas queixas de forma muito bem articulada, considerando sua idade. Entretanto, o vínculo foi se fortalecendo à medida em que Clara se permitia aprofundar em seus sentimentos e ser acolhida em suas angústias.

Ao longo do tratamento, aprofundamos seus temas, como: o surgimento da Bulimia Nervosa; seus sentimentos e as concretizações deles, quando necessárias; suas cenas do passado, algumas abordadas dramaticamente em estratégias de verticalização; como se desenvolveu a baixa autoestima e os medos de se relacionar, dentre outros.

Descreveremos quatro sessões para exemplificar algumas intervenções realizadas. Foram sessões significativas para a melhoria de suas queixas, a partir do relato da própria paciente em sessões posteriores.

\section{Sétima Sessão}

Clara compareceu à sessão muito angustiada, mas afirmava não compreender o motivo para tal angústia. Dizia que sentia algo negativo sobre si. Foi solicitado que a paciente descrevesse em uma palavra o sentimento que tinha a seu respeito, e ela afirmou: "Estou frustrada comigo!". Realizamos um trabalho de concretização da frustração. 
Fizemos um aquecimento no qual pedi para Clara caminhar pela sala e se recordar de situações nas quais se sentiu frustrada consigo e que tentasse trazer tal emoção para o presente. A paciente se recordou que o sentimento de frustração aparecia principalmente quando vomitava após episódios de compulsão alimentar, bem como em momentos nos quais era agressiva verbalmente com seus familiares.

Iniciamos a dramatização do momento em que Clara se sente frustrada no banheiro após vomitar. Foi solicitado que ela assumisse o personagem da "frustração". Foi questionado ao personagem o que fazia com Clara, ele respondeu que a sufocava. Foi pedido que o personagem demonstrasse como sufocava a Clara e então ele se sentou em cima dela (que estava sendo representada por uma almofada) e lhe disse: "você não é capaz de ser alguém melhor, nem no seu físico nem em suas relações?".

Foi solicitado que a paciente assumisse seu lugar novamente, com a almofada por cima de seu rosto (representando o personagem "frustração"), sufocando-a e repetindo a fala anteriormente relatada.

Quando lhe foi questionado sobre outras situações em que se sentia sufocada, como naquele momento, a paciente não soube responder. Foi realizado, assim, um duplo sobre o sentimento de Clara: "Me sinto sufocada com cobranças em minhas relaçôes familiares, que me criticam pelo meu peso e por ser emotiva. Tento o tempo todo provar que sou boa, mas me sinto desrespeitada". A paciente concordou e foi pedido que ela dissesse, em suas palavras, o que a terapeuta havia dito.

Tal duplo foi possível a partir de alguns relatos que a paciente já havia verbalizado, como por exemplo:

Ultimamente tô me sentindo muito errada. Não só fisicamente, mas minha cabę̧a, como se meu jeito de funcionar fosse errado. Em querer entender muito as coisas, aprofundar em tudo, não ser superficial. As pessoas não conseguem entender por que quero relações tão profundas. As pessoas não são assim e apontam isso como se fosse um defeito.

Nota-se, nesse contexto, a utilização, por parte de Clara, de processos cotransferenciais, que para Aguiar (1998) são aprendizados de condutas que se repetem nas relações atuais. A paciente tenta corresponder às expectativas alheias, com uma lógica afetiva de conduta que adotou desde criança, em sua matriz de identidade. Para Clara, havia "algo de errado" com ela, o que resultou em condutas conservadas do personagem da "boazinha" em busca de aceitação e pertencimento.

No compartilhamento, abordamos como é sufocante engolir desrespeitos e observamos como a Bulimia Nervosa pertencia a esse sufocamento e ao desejo de retirar pesos em todos os sentidos. Clara ficou surpresa com a descoberta dessa perspectiva.

Nas sessões seguintes, a paciente trouxe os sintomas da Bulimia Nervosa, e tivemos oportunidades de compará-los com sua dinâmica psíquica. Ela disse: "eu como em excesso, até que de alguma forma preciso colocar tudo para fora e vomito, o que me traz sentimento de culpa".

Seu corpo e seu comportamento em relação ao corpo reproduzem sua dinâmica psíquica, pois ela "engole” os desrespeitos e as cobranças. Mas, de alguma forma, precisa colocar para fora tudo o que foi acumulado, acaba sendo agressiva verbalmente com o outro e isso lhe traz sentimento de culpa. Assim, trabalhamos suas emoções para além do diagnóstico, a partir de uma perspectiva de construção do sintoma como dinâmica psíquica e relacional.

Através de seus relatos e modalidades vinculares, pode-se afirmar também a existência da lógica afetiva de conduta "se eu me defender, serei rejeitada", motivo pelo qual opta por não se posicionar (ou "engolir tudo") perante as cobranças exacerbadas e os desrespeitos que sofre.

Clara sofre grande influência, em suas relações, do papel complementar interno patológico que foi internalizado quando era criança, em diversas cenas em casa ou em ambientes sociais, que lhe dizia: "Você é gorda!", "Você é sensivel demais?". Esse papel complementar a sufocou e continua a sufocá-la, quando se atualiza no presente. Verifica-se nesse papel complementar a influência sociocultural dos padrões da estética midiática em relação ao corpo ideal.

Segundo Albino e Macêdo (2014), a mídia estabelece o padrão da magreza como ideal a ser seguido, fazendo com que pessoas fora de tais medidas se sintam insatisfeitas e pressionadas a corresponderem aos ideais impostos. Essa pressão é sentida por Clara em suas relações, também influenciadas por tais padrões socioculturais, que a levam ao adoecimento.

Tal papel complementar favoreceu a adoção de condutas conservadas por parte da paciente, como adotar práticas compensatórias após as compulsões alimentares, calar-se em determinados momentos e, em outros, agredir. Essas condutas 
bloquearam sua espontaneidade-criatividade e anularam a expressão do eu. Com isso, a paciente se sente insatisfeita consigo e frustrada, o que estimula também a autoagressividade.

A agressividade consigo era, portanto, uma das formas de a Bulimia Nervosa se manifestar, em termos de corporalidade e de comportamentos em relação ao corpo.

\section{Décima Primeira Sessão}

A paciente compareceu ansiosa à sessão, afirmando que não se sente boa o suficiente em suas relações amorosas. Ela traz esse relato com considerável frequência.

Para aprofundar o aquecimento sobre essa sensação, foi perguntada sobre as situações que a fizeram não se sentir boa o suficiente. E ela encontrou cenas passadas, possivelmente matrizes desse conflito, que puderam ser trabalhadas.

Montamos uma cena aberta, escolhida por Clara, de quando tinha 10 anos, na estratégia de verticalização ao passado (Nery, 2012). Nessa estratégia, a cena do passado é presentificada no aqui e agora da realidade suplementar, própria do cenário imaginário (como se) do Psicodrama. Ela está no intervalo da escola e pede um biscoito do lanche de sua amiga. Um colega, nesse instante, a chama de "gorda". Esse momento se torna um dos fundamentais na criação da sua autoimagem crítica e distorcida.

$\mathrm{Na}$ dramatização, a paciente expressou sua vergonha e tristeza naquele contexto. Mas, quando foi solicitada a inversão de papéis, ela não conseguiu entrar no personagem do colega. A terapeuta, então, avisou-a que tomaria o lugar desse personagem e fez falas relacionadas também a um papel complementar interno patológico, que já haviam sido narradas em outras sessões, como: "Você é feia", "sua gorda!" e "precisa comer menos!".

Clara começou a chorar muito, dizendo: "não entendo como alguém pode dizer coisas tão cruéis a outra pessoa". Após a continência desse choro, quando ela expressou seus sentimentos, foi pedida a técnica do espelho, ou seja, que ela voltasse ao aqui e agora, olhasse de fora a cena em que tinha 10 anos e observasse os personagens, representados por almofadas (almofadas - dentre outros objetos — são um dos principais objetos intermediários que contribuem para o fomento da imaginação na realidade suplementar).

Nesse distanciamento, a adolescente falou para o colega: "Vocêfoi muito cruel, ela é apenas uma criança. Você que deveria ter vergonha de ser assim, tão fútil e insensivel". Posteriormente aconselhou à personagem "Clara criança" que soubesse reconhecer suas qualidades e não deixasse os outros ditarem quem ela é.

Ao ser questionada se gostaria de fazer algo para mudar aquela cena, a adolescente chutou para longe o colega e abraçou a "Clara criança". A terapeuta pediu para ela ficar o tempo dela nesse abraço, registrando em seu coração esse novo momento como força para sua vida.

Nessa sessão, a cena reparatória surge a partir do trabalho de uma cena "matriz" da criança interna ferida da paciente. A cena reparatória é quando o protagonista consegue fazer diferente em relação às condutas conservadas e liberar sua espontaneidadecriatividade bloqueada (Nery, 2012). Clara, na realidade suplementar, afastou quem the fazia mal e acolheu a criança.

No compartilhamento, Clara afirma que está desenvolvendo, aos poucos, condições de se acolher em sua realidade diária e afastar quem lhe faz mal, ou seja, concluímos que está alcançando a catarse de integração ${ }^{3}$.

Observamos que suas relações amorosas ficam aprisionadas em cenas de seu corpo, que padece com a Bulimia Nervosa. Seu corpo se humilha perante algumas discriminações e também se rejeita, o que gera um processo de retroalimentação sociométrica de exclusões sociais.

Nesse sentido, a Bulimia Nervosa também se torna um personagem psicodramático que impulsiona a pessoa ao paradoxo do prazer desconfortável, com culpas, como forma de existência.

Nesta sessão, observamos a utilização de processos cotransferenciais por parte de Clara em suas relações, com atuação do papel complementar interno patológico. A paciente internaliza falas de um papel complementar da infância, toma-as para si como verdade, fazendo com que se sinta inadequada e insuficiente em suas relações atuais.

3.A catarse de integração ocorre quando "seu próprio eu tem a oportunidade de se reencontrar e se reordenar [...] ganhar um sentimento de força e alívio"(Moreno,1974,p.113). 
Com isso, pode-se dizer, confirmando nossa hipótese, de que a Bulimia é uma forma de expressão do corpo que carrega cenas socioculturais. A paciente adota comportamentos bulímicos em uma tentativa de se sentir menos inadequada e obter os alimentos psíquicos desejados, como: aceitação, reconhecimento e pertencimento. Necessidade esta vinda da atuação do papel complementar interno patológico, que carrega preconceitos culturais, atuantes na vida de Clara.

Segundo Becker (1999 como citado em Russo, 2005, p. 81), “as pessoas aprendem a avaliar seus corpos através da interação com o ambiente, assim sua autoimagem é desenvolvida e reavaliada continuamente durante a vida inteira”. Dessa forma, o presente caso nos mostra o impacto da relação de Clara com o meio, da sua matriz de identidade dinâmica e presente na construção de sua imagem corporal.

\section{Décima Nona Sessão}

A paciente disse que nessa semana se lembrou de que, após o ocorrido com o colega que a chamou de gorda, começou a se pesar várias vezes ao dia, e se sentia muito mal quando via que seu peso havia aumentado.

Realizamos um Psicodrama interno relacionado a essa cena. Foi pedido que Clara fechasse os olhos, relaxasse o corpo e montasse a cena internamente. Iniciamos a dramatização com a revivência desses momentos em que subia na balança. Foi solicitado que trouxesse para o momento atual todos os pensamentos e sentimentos que afloravam nessas circunstâncias. Em seguida, foi pedido um solilóquio das emoções que estava vivenciando no momento em que subia na balança, e a paciente afirmou: "Estou muito frustrada e envergonhada".

Foi solicitado que Clara entrasse no personagem da "balança", com finalidade de maior distanciamento emocional, para que a paciente acessasse uma nova perspectiva da cena. Quando foi perguntado ao personagem "balança" a perspectiva de tal cena, ele disse: "Apenas mostro números, não tenho nada a dizer sobre Clara. Só enxergo alguém buscando algo que nunca conseguirá: corresponder a ideais para ter aceitação".

Foi questionado ao personagem "balança": "aceitação de quem?", a paciente retomou — por conta própria — ao seu lugar de Clara atual e afirmou que sempre ouvia sua família — pais e avó - chamando sua irmã de "magrinha”, enquanto lhe falavam que precisava comer menos.

Relata também que sempre ouviu, destes mesmos familiares, que era uma criança muito sensível, chorona e desastrada, algo que a paciente toma para si como verdade. Podemos avaliar aqui o impacto do papel complementar interno patológico sobre sua criança interna ferida, que resulta em relações sofridas atualmente. Clara afirma estar sempre disponível e agradando a todos, por medo de não ser boa o suficiente para os outros.

A “incorporação" da matriz de identidade atualizada no aqui e agora de seu corpo nos desvela relações familiares e socioculturais que adoecem a paciente. É preciso comer para ter prazer, relacionar-se, sentir-se existindo, e é preciso vomitar para retirar o que a sufoca nessa existência. Constante paradoxo do vazio e da falta que precisam ser preenchidos, que são preenchidos, mas proibidos, que retornam ao vazio.

Segundo Silva (2010, p. 43), o paciente acredita que "ingerindo mais comida vai conseguir descarregar a tensão advinda das faltas psicológicas que causaram a sensação de insatisfação”. No presente caso, a paciente apresenta grande insatisfação com a falta de reconhecimento e aceitação por parte de sua matriz de identidade, resultando em uma busca desenfreada por prazer, que só se dá através da comida.

A paciente relata, ainda, que atualmente continua ouvindo comentários por parte de sua mãe a respeito de seu corpo e nota que suas amigas não ganham peso facilmente como ela. Esses fatos reforçam sua criança interna ferida, atuando negativamente em sua imagem corporal e, consequentemente, em sua autoestima.

\section{Trigésima Quarta Sessão}

Clara relata que sente não ser digna de obter reciprocidade em suas relações.

Foi questionada sobre a primeira vez em que se sentiu assim, e ela citou sua irmã, com a qual sempre foi afetuosa, mas sente receber frieza em troca. Sabe que sua irmã se preocupa, mas no trato diário se sente rejeitada por ela. 
Montamos a cena de rejeição relatada pela paciente. Representamos sua irmã com uma almofada e nos aquecemos em relação ao que ocorria. Foi pedido para Clara expressar o que gostaria de dizer à irmã, considerando a relação atual entre elas. A paciente disse:

Não aguento mais lidar com os conflitos, pois quando quero falar, você não me escuta e você diz que eu não te escuto. Quero mais empatia, pois até nossa mãe me escuta mais do que você, que é minha irmã! Gostaria que tivéssemos maior proximidade.

Clara entrou no personagem da irmã e passei a ser a personagem Clara, reproduzindo sua fala e fazendo também duplos de que admirava muito a irmã, mas me sentia rejeitada na situação e que gostaria que encontrássemos uma forma de sermos mais próximas e companheiras.

A paciente, na personagem da irmã, não quis se posicionar, mas teve a percepção de que a irmã provavelmente não sabe que ela se sente assim e que talvez seria uma boa possibilidade conversar. Nota-se aqui o início da desconstrução da sua lógica afetiva de conduta "se eu me posicionar, serei rejeitada”, com o reconhecimento da importância da assertividade nas suas relações.

Nesta sessão fica evidente a admiração de Clara pela irmã. Ao ouvir comentários de seus familiares a respeito de seu corpo, em comparação com comentários sobre o corpo de sua irmã, constitui-se uma lógica afetiva de conduta de que precisa ser magra para ser admirada. Tal lógica é reforçada pela mídia que divulga a imagem de corpos magros como um ideal a ser seguido, desconsiderando aspectos de saúde e diferenças de constituição física entre cada indivíduo (Oliveira et al., 2003).

Assim, no presente caso, a Bulimia passa a ocupar o lugar de uma prática em busca de afetos relacionais. Por trás da busca pela perda de peso, encontra-se a necessidade de ser reconhecida, aceita e admirada em suas relações. Isso promove modalidades vinculares em sofrimento, dado que a paciente busca a todo custo agradar aos que estão ao seu redor, abnegando de si, até o momento em que não mais suporta e é agressiva verbalmente.

\section{ANÁLISE DO MOMENTO ATUAL}

Atualmente, a paciente encontra-se em acompanhamento com outra profissional da clínica. Durante o nosso processo terapêutico, observamos sua evolução, pelo fato de não apresentar mais episódios bulímicos e através de seus relatos, como: "Agora me aceito melhor, como o que tenho vontade e voltei a fazer exercício físico, mas sem tanta cobrança" e "sexta eu quis ir para uma festa com um vestido que não fechou em mim. Nem me importei, apenas troquei o vestido".

Segundo Bradshaw (1988 como citado por Cukier, 2017), a criança tem quatro características naturais que a fazem um ser humano: valorizável ${ }^{4}$, vulnerável $^{5}$, imperfeita ${ }^{6}$ e com pensamento concreto e radical ${ }^{7}$, precisando ser reconhecida nessas quatro características como necessidade de dependência básica do ser humano.

Ao não ter tal necessidade de dependência correspondida, surge a criança interna ferida, que foi o caso da paciente em questão. Anteriormente, a paciente não se percebia como alguém valorizável, por ser criticada pela quantidade de comida ao se alimentar e ao se comparar com sua irmã.

Além disso, sempre ouviu críticas a respeito de ser "desastrada"(sic) e de sua sensibilidade, que a faz chorar em situações de conflitos. Atualmente, a paciente apresenta maior reconhecimento do eu e aceitação de si: "Não vou mais ficar correndo atrás de quem eu não acho que vale a pena, só pra ter reconhecimento de como posso ser boa, porque eu já sei me valorizar e sei quem sou".

Clara não se permitia ser alguém vulnerável e imperfeita, autocriticando-se excessivamente e evitando expor seus sentimentos/pensamentos, que se acumulavam até o momento em que expunha tais emoções de forma agressiva.

Com isso, recebia críticas, como sendo "chorona" "explosiva". Atualmente, a paciente se permite viver suas emoções no momento em que aparecem, para tentar compreendê-las e a partir disso tomar atitudes favoráveis à resolução do conflito:

4. Depende da estima e dedicação que seus pais a oferecem para a absorção desse valor.

5. Depende da proteção dos pais, por não ter sistema de defesas desenvolvido.

6. Aprende por meio de tentativa e erro ou modelos.

7. O que leva a criança a acreditar no que dizem que ela é, de forma polarizada. 
"Tenho feito algo que está me fazendo bem: quando tem algo que fica dentro de mim me incomodando, me permito sentir aquilo e então fico bem, sem descontar em outras pessoas ou na comida".

Por fim, Clara também se autocriticava por ser radical em sua forma de pensar e agir, característica essa que ainda estava sendo trabalhada, mas que a paciente já reconhecia e aceitava:

Só de me conhecer, perceber que meu jeito é intenso e que nem todo mundo é assim, já me deu outra perspectiva de que preciso selecionar para quem me abro. Não vou mais me abrir com qualquer um. Vou buscar o que quero e não vou ficar correndo atrás de quem não está na mesma página que eu. Não sou eu quem está perdendo, não tem nada de errado comigo, a culpa é de ninguém, apenas não estávamos na mesma página por dificuldades de cada um, e temos que aceitar isso.

Pode-se dizer, ainda, que a paciente apresentou reconstrução de sua imagem corporal, aceitando seu corpo tal como ele é, aprendendo a reconhecê-lo e admirá-lo sem a necessidade da aprovação de sua matriz de identidade. Há falas da paciente, como: "Eu estou amando meu corpo. Essas últimas semanas eu paro no espelho e falo: 'tu é gata!" e "Percebi que engordar ou emagrecer não muda quem eu sou, eu sou quem sou e vou me aceitar!".

O trabalho realizado das lógicas afetivas de conduta elaboradas pela paciente e da sua criança interna ferida resultou no progresso de sua perspectiva a respeito da imagem corporal, amenizando gradualmente os sintomas da Bulimia, até cessarem.

\section{CONSIDERAÇÕES FINAIS}

Neste artigo apresentamos os resultados alcançados da psicoterapia psicodramática de uma adolescente que sofria de Bulimia Nervosa. E também respondemos às perguntas que fizemos ao longo da pesquisa.

Em primeiro lugar, respondemos positivamente à pergunta sobre se a Bulimia Nervosa é um clamor sociocultural do corpo. Nas sessões com a adolescente, por meio de seus sintomas, seu corpo clamou e trouxe cenas de sua matriz de identidade.

A Bulimia Nervosa apresenta o corpo que carrega a sociedade capitalista e do espetáculo, que cultua a beleza corporal midiática como um dos principais requisitos para a conquista sociométrica do pertencimento e da aceitação grupal.

No cenário psicodramático, o corpo atuou as cenas que bloqueavam a espontaneidade-criatividade (E-C) e produziam a Bulimia Nervosa. Nessas cenas, a criança interna ferida e o papel complementar interno patológico se expressavam, com suas lógicas afetivas de conduta.

As sessões descritas e as demais sessões realizadas com a paciente desvelaram conteúdos coinconscientes de suas cenas. Por meio da cocriação, o enfoque terapêutico da criança interna ferida, do papel complementar patológico e das lógicas afetivas de conduta foi um meio de resgate da espontaneidade-criatividade da paciente. Associados a esses aspectos, trabalhamos as condutas conservadas que causavam sofrimento sociopsíquico. No processo, a paciente desenvolveu novas formas de se relacionar e de condutas, que promoveram a melhora do quadro de Bulimia Nervosa

Em sua vida, a paciente aprendeu algumas lógicas afetivas de conduta disfuncionais, envolvendo sua imagem corporal, construindo o quadro de Bulimia Nervosa como expressão de sua dinâmica psíquica. Essas lógicas foram desconstruídas durante o acompanhamento, fato que pôde ser percebido através de falas da paciente, como: "me tornei mais seletiva com meus amigos, não fico tentando mais ser supersimpática (no sentido de agradar) com todo mundo. Sei com quem posso contar".

Observamos, portanto, que a ressignificação de experiências de sofrimentos, por meio do Psicodrama, contribui para o desbloqueio da espontaneidade-criatividade e para a criação de modalidades vinculares menos sofridas.

Quanto à imagem corporal negativa da paciente, ela foi desenvolvida a partir de perspectivas socioculturais que lhe foram impostas desde criança, em sua matriz de identidade. Essas perspectivas reforçaram lógicas afetivas adoecedoras.

Concluímos que o enfoque terapêutico utilizado contribuiu para que Clara conseguisse alcançar algumas catarses de integração para situações, antes mal resolvidas, de sua criança interna ferida. A psicoterapia avançou, trabalhamos 
novos temas para além de seu sofrimento de quando criança a respeito de seu corpo e modo de ser. Coletamos falas do diário da paciente, que nos foi apresentado:

Você é especial, longe de ser qualquer uma. Você éforte, está sempre disposta a mudar e se tornar uma pessoa melhor. Você é verdadeira, não precisa esconder o que sente e sabe usar isso para ajudar as pessoas. Você é linda, e sua beleza é só sua (é única). Você não precisa se comparar a ninguém. Tá tudo bem ser do jeitinho que você é.

As novas respostas a conflitos com os quais precisava lidar há muito tempo e não conseguia abordá-los começaram a surgir: por exemplo, quando notou que seria a melhor alternativa conversar com sua irmã que a rejeitava, sobre como se sentia na relação, com maior assertividade.

Buscamos tratar a paciente como pessoa em toda sua complexidade e não apenas como sintoma, pois como se pode observar, seus sintomas de Bulimia Nervosa eram apenas a ponta do iceberg para questões emocionais e socioculturais mais profundas.

O estudo oferece como contribuição um olhar sobre a riqueza do Psicodrama como tratamento para casos de transtornos alimentares e formas de atuação em quadros semelhantes, principalmente tratando-se da infância e da adolescência. Nesses períodos ocorrem diversas alterações corporais e está se formando a imagem corporal, que nem sempre corresponderá ao que é esperado pelos padrões impostos pela sociedade.

Sugerimos que seja realizado um acompanhamento mais próximo à família, como forma de ampliação da rede de apoio para o adolescente. Sugerimos também que, em próximas pesquisas sobre o tema, sejam aprofundadas as questões midiáticas e culturais envolvidas no caso, pois é a atuação aqui e agora da matriz de identidade. Infelizmente, devido aos temas protagônicos ou emergentes, tais questões foram pouco abordadas no processo psicoterápico apresentado.

\section{CONTRIBUIÇÃO DOS AUTORES}

Conceitualização: Guimaraes JS, Nery MP; Investigação: Guimaraes JS, Nery MP; Escrita - Rascunho Original: Guimaraes JS, Nery MP; Escrita - Revisão e Edição: Guimaraes JS, Nery MP.

\section{AGRADECIMENTOS}

Não se aplica.

\section{DISPONIBILIDADE DE DADOS DE PESQUISA}

Não se aplica.

\section{FINANCIAMENTO}

Não se aplica.

\section{REFERÊNCIAS}

Aguiar, M. (1998). Teatro espontâneo e psicodrama. Ágora.

Albino, E. B.S. \& Macêdo, E. M.C (2014). Transtornos alimentares na adolescência: Uma revisão de literatura. Veredas Favip, 7(1), 108-129.

Brito, V. (2006). Um convite à pesquisa: epistemologia qualitativa e psicodrama. In A. M. Monteiro, D. Merengué \& V. Brito, Pesquisa qualitativa e psicodrama (pp. 15-56). Ágora. 
Bustos, D. M. (2005). O Psicodrama: Aplicações da técnica psicodramática (4a ed.). Ágora.

Cukier, R. (2017). Sobrevivência emocional: As dores da infância revividas no drama adulto (7a ed.). Ágora.

Debord, G. (2007). A sociedade do espetáculo. Appris.

Foucault, M. (2014). Microfísica do Poder (28a ed.) (R. Machado, trad.). Graal. (Trabalho original publicado em 1979).

Guimarães, A. S. A. (2002). Classes, raça e democracia. Fundação de Apoio à Universidade de São Paulo.

Minayo, M. C. S. (2012). Análise qualitativa: Teoria, passos e fidedignidade. Ciência e Saúde Coletiva, 17(3), 621-626. https://doi.org/10.1590/S1413-81232012000300007

Moreno, J. L. (1974). Psicoterapia de grupo e psicodrama. Mestre Jou.

Moreno, J. L. (2014). Psicodrama (13a ed.). Cultrix.

Nery, M. P. (2012). Sociodrama. In M. P. Nery \& M. I. G. Conceição (Orgs.), Intervenções grupais: O psicodrama e seu método. Ágora.

Nery, M. P. (2014). Vinculo e afetividade: Caminho das relações humanas (3a ed.). Ágora.

Oliveira, F. P. de, Bosi, M. L. M., Vigario, P. S., \& Vieira, R. S. (2003). Comportamento alimentar e imagem corporal em atletas. Revista Brasileira de Medicina do Esporte, 9(6), 348-356. https://doi.org/10.1590/S1517-86922003000600002

Russo, R. (2005). Imagem corporal: Construção através da cultura do belo. Movimento E̋ Percep̧̧ão, 5(6), 80-90.

Silva (2010). Distúrbios funcionais. In V. R. C. S. Dias, Psicopatologia e psicodinâmica na análise psicodramática: Volume III (pp. 31-68). Ágora. 